\title{
Polarizable molecular dynamics simulation of $\mathrm{Zn}(\mathrm{II})$ in water using the AMOEBA force field
}

\author{
Johnny C. Wu ${ }^{\dagger}$, Jean-Philip Piquemal ${ }^{\ddagger}, \S^{,}{ }^{\star}$, Robin Chaudret ${ }^{\ddagger}, \S$, Peter Reinhardt ${ }^{\ddagger}, \S$, and \\ Pengyu Ren ${ }^{\dagger},{ }^{*}$ \\ † Department of Biomedical Engineering, University of Texas at Austin, Austin, Texas \\ 78712-1062, USA \\ ‡ UPMC Univ. Paris 06, UMR 7616, Laboratoire de Chimie Théorique, case courrier 137, 4 place \\ Jussieu, F-75005, Paris, France \\ $\S$ CNRS, UMR 7616, Laboratoire de Chimie Théorique, case courrier 137, 4 place Jussieu, \\ F-75005, Paris, France
}

\begin{abstract}
The hydration free energy, structure, and dynamics of the zinc divalent cation are studied using a polarizable force field in molecular dynamics simulations. Parameters for the $\mathrm{Zn}^{2+}$ are derived from gas-phase $a b$ initio calculation of $\mathrm{Zn}^{2+}$-water dimer. The Thole-based dipole polarization is adjusted based on the Constrained Space Orbital Variations (CSOV) calculation while the Symmetry Adapted Perturbation Theory (SAPT) approach is also discussed. The vdW parameters of $\mathrm{Zn}^{2+}$ have been obtained by comparing the AMOEBA $\mathrm{Zn}^{2+}$-water dimerization energy with results from several theory levels and basis sets over a range of distances. Molecular dynamics simulations of $\mathrm{Zn}^{2+}$ solvation in bulk water are subsequently performed with the polarizable force field. The calculated first-shell water coordination number, water residence time and free energy of hydration are consistent with experimental and previous theoretical values. The study is supplemented with extensive Reduced Variational Space (RVS) and Electron Localization Function (ELF) computations in order to unravel the nature of the bonding in $\mathrm{Zn}^{2+}\left(\mathrm{H}_{2} \mathrm{O}\right)_{n}(\mathrm{n}=1,6)$ complexes and to analyze the charge transfer contribution to the complexes. Results show that the importance of charge transfer decreases as the size of $\mathrm{Zn}$-water cluster grows due to anticooperativity and to changes in the nature of the metal-ligand bonds. Induction could be dominated by polarization when the system approaches condensed-phase and the covelant effects are eliminated from the $\mathrm{Zn}$ (II)-water interaction. To construct an "effective" classical polarizable potential for $\mathrm{Zn}^{2+}$ in bulk water, one should therefore avoid over-fitting to the ab initio charge transfer energy of $\mathrm{Zn}^{2+}$-water dimer. Indeed, in order to avoid overestimation of condensed-phase many-body effects, which is crucial to the transferability of polarizable molecular dynamics, charge transfer should not be included within the classical polarization contribution and should preferably be either incorporated in to the pairwise van der Waals contribution or treated explicitly.
\end{abstract}

\footnotetext{
*Corresponding authors: Jean-Philip Piquemal (UPMC) or Pengyu Ren (Austin). jpp@ @1ct.jussieu.fr, pren@mail.utexas.edu. Supporting Information Symmetry adapted Perturbation Theory (SAPT) results for the water-Zn(II) complex. This information is available free of charge via the Internet at http://pubs.acs.org/.
} 


\section{Keywords}

Zinc; polarizable force field; AMOEBA; molecular dynamics; free energy; Electron Localization

Function; Topological Analysis; Population Analysis; Charge Transfer

\section{INTRODUCTION}

Since the 40's, we begin to appreciate that specific biological functions critically depend on the presence of zinc. ${ }^{1}$ Moreover, its divalent cation, $\mathrm{Zn}^{2+}$ play an important role in many metalloenzymes by acting directly as a structural element in proteins such as Zn-fingers ${ }^{2}$ or by serving as a cofactor. ${ }^{3}$ Due to zinc's soft character and the subtle nature of its interactions with the biological environment, ${ }^{4}$ Quantum Mechanics $(\mathrm{QM})$ is usually the primary methodology for the study of $\mathrm{Zn}^{2+}$-metalloproteins. ${ }^{5-7}$ Of course, such an approach is limited to "static" structures of relatively small biomimetic models due to the high computational demands by state of the art QM approaches. Hybrid methods that combine $\mathrm{QM}$ and molecular mechanics $(\mathrm{QM} / \mathrm{MM})^{8-11}$ offer the possibility to treat the whole protein on longer time scales. Nevertheless, if one is interested in the dynamical behavior of $\mathrm{Zn}^{2+}$ complexes, available methods remain sparse. Traditional fixed charge force fields are unable to capture the interactions between $\mathrm{Zn}^{2+}$ and its ligands, or even to keep the $\mathrm{Zn}^{2+}$ "in place", unless using artificial bonds ${ }^{12}$ or extra charge sites. ${ }^{13}$ Recent studies based on quasichemical theory have shown the importance of polarization in ion hydration. ${ }^{14,} 15$

As an alternative to QM, anisotropic polarizable molecular mechanics (APMM) methods, such as SIBFA (Sum of Interactions Between Fragments $a b$ initio Computed) ${ }^{16,17}$ and AMOEBA ${ }^{18}$ have been developed in recent years. Such techniques are computationally more efficient and provide potential energy surfaces in close agreement with QM. For the specific case of $\mathrm{Zn}^{2+}$, SIBFA, which treats both polarization and charge transfer contributions, has shown to be particularly accurate and enabled the study of large biological systems. ${ }^{16,}{ }^{19-23}$ As SIBFA's extension to MD is under development, AMOEBA has already been extensively tested in simulations of various systems including proteins ${ }^{24-26}$ and has been shown to be particularly suited for the computation of dynamical properties of metal cations of biological interest. ${ }^{19-22,27-29}$

In this contribution, as a first step towards modeling $\mathrm{Zn}^{2+}$ metalloenzymes, we will show that AMOEBA is able to accurately capture $\mathrm{Zn}^{2+}$ solvation properties. In the first part of this work, we will detail the parameterization process which is grounded on gas phase ab initio calculations following a "bottom-up" approach. ${ }^{16}$ The application of energy decomposition analyses (EDA) techniques ${ }^{17}$ such as the Constrained Space Orbital Variations (CSOV), ${ }^{30}$ RVS (Reduced Variational Space (RVS) ${ }^{31}$ and Symmetry Adapted Perturbation Theory $(\mathrm{SAPT})^{32}$ to AMOEBA s parameterization will be discussed. Moreover, such approaches are used to evaluate the importance of the charge transfer contribution. The nature of the interaction of $\mathrm{Zn}^{2+}$ with water will be investigated using the Electron Localization Function $(E L F)^{33}$ topological analysis. ${ }^{34}$ In the second part, we will perform extensive condensedphase simulations using AMOEBA to compute $\mathrm{Zn}^{2+}$ solvation properties such as the ionwater radial distribution function (RDF), water residence times, coordination number as well as the solvation free energy. Comparison is made to experimental results as well as other divalent cations that have previously been studied using AMOEBA. 


\section{COMPUTATIONAL DETAILS}

\section{Gas phase ab initio calculations}

The intermolecular interaction energies of $\mathrm{Zn}^{2+}-\mathrm{H}_{2} \mathrm{O}$ at various separations were calculated using GAUSSIAN $03^{35}$ at the MP2(full) level. Basis Set Superposition Error (BSSE) correction was included in the binding energy. The geometry of the previously derived AMOEBA water model was applied. ${ }^{36,37}$ The aug-cc-pVTZ basis set ${ }^{38}$ was employed for water and the 6-31G(2d,2p) basis setfor the $\mathrm{Zn}^{2+}$ cation. Post-Hartree Fock Symmetry Adapted Perturbation Theory (SAPT) calculations were performed with the same basis sets at the MP2 and CCSD level using the Dalton package ${ }^{38}$ and the SAPT $96 .{ }^{39}$ CSOV polarization energy calculations were performed using a modified version ${ }^{40}$ of HONDO95. $3^{40}$ with the B3LYP methods ${ }^{41,} 42$ using the above basis sets. The $\mathrm{Zn}^{2+}$ atomic polarizability was computed using GAUSSIAN 03 at the MP2(full)/6-31G** level.

Additional energy decomposition analysis was performed on zinc hydrated cluster with the Reduced Variational Space (RVS) scheme as implemented in the GAMESS ${ }^{43}$ software. The RVS energy decomposition computations were performed at the Hartree-Fock (HF) level using the CEP 4-31G(2d) basis set ${ }^{44}$ augmented with two diffuse $3 d$ polarization functions on heavy atoms (double zeta quality pseudopotential) and at the aug-cc-pVTZ basis set level $\left(6-31 \mathrm{G}^{* *}\right.$ for $\left.\mathrm{Zn}(\mathrm{II})\right)$.

\section{Electron Localization Function analysis (ELF)}

In the framework of the ELF ${ }^{33}, 45$ topological analysis, ${ }^{34}$ the molecular space is divided into a set of molecular volumes or regions (the so-called "basins") localized around maxima (attractors) of the vector field of the scalar ELF function. The ELF function can be interpreted as a signature of the electronic-pair distribution and ELF is defined to have values restricted between 0 and 1 to facilitate its computation on a 3D grid and its interpretation. The core regions can be determined (if $Z>2$ ) for any atom A. Regions associated to lone pairs are referred to as $\mathrm{V}(\mathrm{A})$ and bonding region denoting chemical bonds are denoted $\mathrm{V}(\mathrm{A}, \mathrm{B})$. The approach offers an evaluation of the basin electronic population as well as an evaluation of local electrostatic moments. It is also important to point out that metal cations exhibit a specific topological signature in the electron localization of their density interacting with ligands according to their "soft" or "hard" character. Indeed, a metal cation can split its outer-shell density (the so-called subvalent domains or basins) according to its capability to form a partly covalent bond involving charge transfer. ${ }^{46}$ More details about the ELF function and its application to biology can be found in a recent review. ${ }^{47}$ All computations have been performed using a modified version ${ }^{48}$ of the Top-Mod package. ${ }^{49}$

\section{PARAMETERIZATION AND FREE ENERGY SIMULATIONS}

\section{Use of CSOV and SAPT energy decompositions schemes}

Following a procedure that has already shown success with $\mathrm{Ca}(\mathrm{II})$ and $\mathrm{Mg}(\mathrm{II}),{ }^{29}$ the $\mathrm{Zn}^{2+}$ cation is parameterized by first matching the distance-dependence of AMOEBA polarization energies of the ion-water dimer in gas-phase with reference ab initio CSOV polarization energy results. In order to supplement the CSOV decomposition we have also performed SAPT computations (available in Supporting Information). It is important to note that, despite the fact that SAPT could be expected to be the reference analysis offering up to CCSD correlation corrections to compute the contributions, a close examination of the results clearly show that SAPT has problems with converging to the supermolecular interaction energy. A similar trend has recently been observed by Rayon et al. ${ }^{6}$ It appears that difficulty with convergence is mainly due to the second order induction term which consists of both polarization and charge transfer energies. ${ }^{17}$ Such problem is not new as 
Claverie $^{50}$ and then Kutzelnigg ${ }^{51}$ showed 30 years ago that the convergence of the SAPT expansion was not guaranteed. As in recent studies on water, ${ }^{52}$ the discrepancy of total SAPT energies compared to supermolecular interaction energy results can be traced back to the importance of $3^{\text {rd }}$ order induction correction. Their inclusion clearly enhances the binding energy and could therefore improve SAPT results. We reported here extensive SAPT result in a detailed Supporting Information section dealing with the $\mathrm{Zn}^{2+}$-water complex. As one can see from the SI, at the Hartree-Fock level, the SAPT approximation tends not to converge at short-range, the total SAPT energy being far from the supermolecular $\mathrm{HF}$ value. Around the equilibrium $\left(\mathrm{Zn}^{2+}-\mathrm{O}=2.0 \AA\right)$, and beyond, this discrepancy tends to diminish, becoming negligible at long-range. However, since the AMOEBA force field is based on the reproduction of supermolecular interaction energies, we need short-range induction data in order to refine the parameters. Moreover, as SAPT induction embodies both charge transfer and polarization, we cannot fit directly the sole "polarization only" Thole model to these values. Consequently, for the present purpose of AMOEBA's fitting, we have limited our use of the SAPT results to comparison of the accuracy of AMOEBA's Halgren 14-7 van der Waals function ${ }^{53}$ at long range by a direct comparison to the sum of the SAPT exchange -repulsion, dispersion and exchangedispersion. Such fit is reflected in the good agreement between the AMOEBA and ab initio total interaction energy at long-range (see Figure 5).

In summary, we fit AMOEBA's polarization contribution (the damping factor " $a$ " in the next section) to the CSOV results. The remaining induction contribution (charge transfer) will be included in the van der Waals term as a result of matching the total binding energy of AMOEBA to that of QM. In the absence of an explicit charge transfer term, such strategy is justified as the charge transfer contribution is notably smaller in magnitude compared to polarization $4,16,22,23$ and a good percentage of it (namely the 2-body part) could be accurately included within AMOEBA's van der Waals term assuming that many-body charge transfer is not the driving force of $\mathrm{Zn}$ (II) solvation dynamics. The validity of such assumption and the applicability of the present parameterization scheme to $\mathrm{Zn}^{2+}$ will be discussed in the first section of the discussion.

\section{AMOEBA calculation details}

The AMOEBA polarizable force field ${ }^{28,36,37}$ is used to study the solvation dynamics of $\mathrm{Zn}(\mathrm{II})$. Hence, the electrostatic term of the model accounts for polarizability via atomic dipole induction

$$
\mu_{i, \alpha}^{\text {ind }}=\alpha_{i}\left(\sum_{\{j\}} T_{\alpha}^{i j} M_{j}+\sum_{\left\{j^{\prime}\right\}} T_{\alpha \beta}^{i j^{\prime}} \mu_{j^{\prime}, \beta}^{\text {ind }}\right) \text { for } \alpha, \beta=1,2,3
$$

where $M_{j}=\left[q_{j}, \mu_{j, 1}, \mu_{j, 2}, \mu_{j, 3}, \ldots\right]^{\mathrm{T}}$ are the permanent charge, dipole, and quadrupole moments, and $T_{\alpha}^{i j}=\left[T_{\alpha}, T_{\alpha 1}, T_{\alpha 2}, T_{\alpha 3}, \ldots\right]$ is the interaction matrix between atoms $i$ and $j$. The Einstein convention is used to sum over indices $\alpha$ and $\beta$. The atomic polarizability, $\alpha_{i}$, is parameterized for the zinc cation in this work. Note that the first term within the parenthesis corresponds to the polarization field due to permanent multipoles, while the second term corresponds to the polarization field due to induced dipoles produced at the other atoms.

The dipole polarization is damped via smeared charge distributions as proposed by Thole ${ }^{54}$ 


$$
\rho=\frac{3 a}{4 \pi} \exp \left(-a u^{3}\right)
$$

where $u=R_{i j} /\left(\alpha_{i} \alpha_{j}\right)^{1 / 6}$ is the effective distance between atom $i$ and $j$. The scalar $a$, a dimensionless parameter corresponding to the width of the smeared charge distribution, is parameterized to be 0.39 for water ${ }^{36}$ and monovalent ions. ${ }^{55}$ Previous study suggested that, for monovalent ions, AMOEBA is able to reproduce ab initio MP2 correlated results and hydration enthalpies without modifying the damping factor. However, since divalent ions, such as $\mathrm{Ca}^{2+}$ and $\mathrm{Mg}^{2+, 28}$ require a wider charge distribution in order to agree with QM ionwater dimer energy, smaller values of $a$ were assigned. The value for $\mathrm{Zn}^{2+}$ is also adjusted from 0.39 and is compared with those of $\mathrm{Ca}^{2+}$ and $\mathrm{Mg}^{2+}$ below.

The repulsion-dispersion (van der Waals) interaction is represented by a buffered 14-7 function $^{53}$

$$
U_{i j}^{\mathrm{buff}}=\varepsilon_{i j}\left(\frac{1+\delta}{\rho_{i j}+\delta}\right)^{n-m}\left(\frac{1+\gamma}{\rho_{i j}^{m}+\gamma}-2\right)
$$

where $\varepsilon_{i j}$ the potential well depth. In addition $\rho_{i j}$ is $R_{i j} / R_{i j}^{0}$ where $R_{i j}$ is the separation distance between atoms $\mathrm{i}$ and $\mathrm{j}$, and $R_{i j}^{0}$ is the minimum energy distance. Following Halgren, we used fixed values of $n=14, m=7, \delta=0.07$, and $\gamma=0.12$. The values for $R_{i j}^{0}$ and $\varepsilon_{i j}$ are parameterized. The polarizable water model as developed by Ren et $\mathrm{al}^{36}$ is employed in this study.

With water geometry fixed, the $\mathrm{Zn}^{2+}-\mathrm{O}$ distance were varied between 1.5 and $5 \AA$. The damping factor " $a$ " was adjusted so that the AMOEBA polarization energy matched the CSOV values as much as possible. Next, parameters for the van der Waals interaction, $R^{0}$ (radius) and $\epsilon$ (well-depth), were derived by comparing the total ion-water binding energy computed by AMOEBA to the ab initio values at various distances. For interactions between different types of atoms, these parameters undergo combination rules as described by Ponder. ${ }^{26}$ The binding energies were computed as the total energy less the isolated water and ion energies at infinite separation distance.

Molecular dynamics simulations were performed via the TINKER 5 package $^{56}$ to compute the solvation free energy of $\mathrm{Zn}^{2+}$. Fourteen independent simulations were first performed to "grow" the Zn vdW particle by gradually varying $\mathrm{R}(\lambda)=\lambda\left(\mathrm{R}_{\text {final }}\right)$ and $\varepsilon(\lambda)=\lambda\left(\varepsilon_{\text {final }}\right)$ where $\lambda=(0.0,0.0001,0.001,0.1,0.2,0.3,0.4,0.5,0.6,0.7,0.8,0.9,1.0)$. Subsequently, 30 simulations were performed to "grow" the $(+2)$ charge of $\mathrm{Zn}^{2+}$ along with its polarizability such that $\mathrm{q}\left(\lambda^{\prime}\right)=\lambda^{\prime}\left(\mathrm{q}_{\text {final }}\right)$ and $\alpha\left(\lambda^{\prime}\right)=\lambda^{\prime}\left(\alpha_{\text {final }}\right)$ where $\lambda^{\prime}=(0.0,0.1,0.2,0.3,0.325,0.350$, $0.375,0.400,0.425,0.450,0.475,0.500, \ldots, 1.0)$. The long-range electrostatics is modeled with particle-mesh Ewald summation for atomic multipoles with a cutoff of $7 \AA$ in real space and $0.5 \AA$ spacing and a 5th-order spline in reciprocal space. ${ }^{57}$ The convergence criteria for induced dipole computation is $0.01 \mathrm{D}$. Molecular dynamics simulations were performed with a $1 \mathrm{fs}$ timestep for $500 \mathrm{ps}$ at each perturbation step. Trajectories were saved every $0.1 \mathrm{ps}$ after the first $50 \mathrm{ps}$ equilibration period. Temperature was maintained using the Berendsen weak coupling method at $298 \mathrm{~K} .{ }^{58}$ The system contained 512 water molecules with one $\mathrm{Zn}^{2+}$ ion and $24.857 \AA$ is the length of each side of the cube. 
The absolute free energy was computed from the perturbation steps by using the Bennett acceptance ratio (BAR), a free energy calculation method that utilizes forward and reverse perturbations to minimize variance. ${ }^{59,} 60 \mathrm{MD}$ simulations were extended for $2.2 \mathrm{~ns}$ (total 2.7 ns) with the final $\mathrm{Zn}^{2+}$ parameters and the resulting trajectory was used in the analysis of the structure and dynamics of water molecules in the first solvation shell. Water molecules separated by a distance less than the first minimum of the $\mathrm{Zn}^{2+}-\mathrm{O}$ RDF were considered to be in the first solvation shell. The averaged residence time of the first shell water molecules was directly measured by monitoring the entering and exit events.

\section{RESULTS AND DISCUSSION}

\section{Contribution of charge transfer in $\mathrm{Zn}^{2+}$-water complexes}

The lack of explicit charge transfer (CT) in AMOEBA presents an interesting challenge. When the CT contribution is significant, despite its limited magnitude in many-body complexes, it may be difficult to capture the overall many-body effect by only considering polarization. Therefore, it is important to investigate the CT contribution to the $\mathrm{Zn}^{2+}$-water interaction energy and its dependence on the system size. To estimate the magnitude of charge transfer, we performed several RVS energy decomposition analysis on complexes up to $\left[\mathrm{Zn}\left(\mathrm{H}_{2} \mathrm{O}\right)_{6}\right]^{2+}$.

We report here complexes that were initially studied by Gresh et al. ${ }^{22,} 61,62$ : monoligated $\left[\mathrm{Zn}\left(\mathrm{H}_{2} \mathrm{O}\right)\right]^{2+}$ complex and polyligated $\left[\mathrm{Zn}\left(\mathrm{H}_{2} \mathrm{O}\right)_{6}\right]^{2+},\left[\mathrm{Zn}\left(\mathrm{H}_{2} \mathrm{O}\right)_{5}\left(\mathrm{H}_{2} \mathrm{O}\right)\right]^{2+}$, and $\left[\mathrm{Zn}\left(\mathrm{H}_{2} \mathrm{O}\right)_{4}\left(\mathrm{H}_{2} \mathrm{O}\right)_{2}\right]^{2+}$ arrangements (octahedral-> pyramidal -> tetrahedral first-shell). As we can see in Table 1, the importance of charge transfer relative to polarization varies with the size of the $\mathrm{Zn}^{2+}-\left(\mathrm{H}_{2} \mathrm{O}\right) n$ complex and depends on the basis set. It makes up a significant portion of induction for a monoligated $\left[\mathrm{Zn}\left(\mathrm{H}_{2} \mathrm{O}\right)\right]^{2+}$ and its contribution decreases as number of ligating water molecules increase to 6 . The charge transfer effect appears to be diluted within the entire induction energy (polarization and charge transfer) as the number of water molecules grows in agreement with previous observation of anti-cooperative effects. 22, 61, 62 Note that basis set superposition error (BSSE) is not taken into account. As indicated by Stone, ${ }^{63}$ such systematic error can be clearly associated with the charge transfer effect. In contrast to the inverse relationship between CT and water ligation expressed by the zinc cation, the CT contribution associated with anions, such as $\mathrm{Cl}^{-}$, has been observed to increase as ligation increases. ${ }^{64}$ This phenomena may be due to the asymmetric solvation environment for the anions as well as their modes of water ligation. However, analyses of CT effects are not apparent as they are found in both induction energy and basis set superposition error. ${ }^{63}$ For the largest complex $\left.\left[\mathrm{Zn}\left(\mathrm{H}_{2} \mathrm{O}\right)_{6}\right]^{2+}\right)$, the BSSE amounts to $3.3 \mathrm{kcal} /$ mol. If removed, the relative weight of charge transfer to the total induction reduces from $16.6 \%$ (Table 1) to $15.3 \%$ at the CEP-31G(2d) level. Using the large aug-cc-PVTZ for water coupled to the $6-31 \mathrm{G}^{* *}$ basis set for $\mathrm{Zn}$ (II), the observed trends are even more pronounced as the relative importance of charge transfer strongly diminishes from $6.4 \%$ of the whole induction for $\left[\mathrm{Zn}\left(\mathrm{H}_{2} \mathrm{O}\right)_{4}\right]^{2+}$ to less than $4 \%$ for the $\left[\mathrm{Zn}\left(\mathrm{H}_{2} \mathrm{O}\right)_{6}\right]^{2+}$ complex while polarization becomes more dominant. Thus the magnitude of the CT estimated by ab initio methods is greatly dependent on the basis set used. While our results have been obtained at the HartreeFock level, recent studies clearly show that correlation acts on induction and leads to greater charge transfer energy. ${ }^{17,}{ }^{40}$ For this reason, we computed the induction energies on selected water clusters at both HF and DFT level using a recently introduced energy decomposition analysis (EDA) technique based on single configuration-interaction (CI) localized fragment orbitals. ${ }^{65}$ We indeed find that the CT contribution increases slightly with DFT, however, overall it accounts for less than $20 \%$ of the total induction energy for monoligated complexes and presumably would be even less in the bulk water environment. 
To gain further insight into the interaction of $\mathrm{Zn}^{2+}$ with water, we performed the Electron Localization Function (ELF) analysis. An important asset of the ELF topological analysis is that is provides a clear description of a covalent bond between two atoms as it exhibits a basin between atoms to indicate electron sharing. Here, we have considered several $\mathrm{Zn}^{2+}$ (water) ${ }_{n}$ complexes, $n=1$ to 6 . An important discovery from ELF analysis is that a covalent $\mathrm{V}(\mathrm{Zn}, \mathrm{O})$ is only observed in the monoligated $\mathrm{Zn}^{2+}$-water complex (Figure 1). In that case, we observe a net concentration of electrons between the zinc cation and the water oxygen, a clear sign of covalent bonding (1.9 e- on the bond). As $n$ increases, the covalent $\mathrm{V}(\mathrm{Zn}, \mathrm{O})$ feature disappears despite a residual mixing of $\mathrm{Zn}^{2+}$ contributions in the oxygen basin. Indeed, as the $\mathrm{Zn}-\mathrm{O}$ distances increase with $n$ (Figure 2 and Figure 3), the $\mathrm{Zn}-\mathrm{O}$ bond becomes more ionic as the charge transfer quickly diminishes. Such behavior could be then understood using the subvalence concept. ${ }^{46}$ As shown by de Courcy et al. ${ }^{4,}, 46$ the cation density is split into several "subvalent" domains as its outer shells appear strongly polarized, which explains why covalency is not achieved. If the cation electron density is strongly delocalized towards the oxygen atoms, the center of the basin remains closer to $\mathrm{Zn}^{2+}$ (covalent bonding would implicate a polarized bond with a covalent $\mathrm{V}(\mathrm{Zn}, \mathrm{O})$ basin localized closer to the more electronegative oxygen). ELF results thus suggest that although the induction in the $\mathrm{Zn}^{2+}$-water monoligated complex is dominated by charge transfer, this is not to the case for $n$ from 2 to 6 . In the latter case, the many-body effects are driven by the $\mathrm{Zn}^{2+}$ outer shells' plasticity that accommodates the strongly polarized water molecules. The Atoms in Molecules (AIM) population analysis confirms that such behavior is present in DFT as well as at the MP2 level. As expected (see ${ }^{6,40}$ for example), DFT tends to slightly over-bind the complexes as compared to MP2 which clearly gives a better description of the bonding over Hartree-Fock.

To conclude on these various results, we expect that AMOEBA will improve in accuracy with increase in system size as the charge transfer effect becomes less important and the total induction will be dominated by polarization. In other words, we anticipate the discrepancy between AMOEBA and QM observed in the monoligated water- $\mathrm{Zn}^{2+}$ complex to disappear in the condensed-phase. This also suggests that an "ad-hoc" inclusion of the charge transfer into the polarization contribution by adjusting the polarization damping scheme (see the Thole model in the Computational Details) is probably not a suitable strategy. Indeed, charge transfer can rapidly vanish, and "polarization only" models overfitted on monoligated complexes to include charge transfer will lead to an overestimated many-body effect in bulk-phase simulation as the polarization would still contain the unphysical charge transfer. Charge transfer should be treated explicitly or included in the van der Waals to certain extent. In this study, we adopt the latter approach to effectively incorporate the charge transfer in the bulk environment into the vdW interactions.

\section{Accuracy of the AMOEBA parameterization}

The distance dependent dimer binding energies were used to adjust vdW parameters ( $\mathrm{R}$ and $\varepsilon)$ and the damping factor of polarizability $(a)$ for $\mathrm{Zn}^{2+}$ was adjusted to match the CSOV polarization energy. Table 2 lists the final parameters of the $\mathrm{Zn}^{2+}$ cation as well as the $\mathrm{Mg}^{2+}$ and $\mathrm{Ca}^{2+}$ cations parameterized by Jiao et al. ${ }^{28}$ that are optimized for the Tinker implementation of AMOEBA Meanwhile, parameters optimized for a slightly modified implementation of the AMOEBA force field present in Amber which embodies a modified periodic boundary condition treatment of long range van der Waals are available as well. ${ }^{29}$ It should be noted that although the previously reported parameters for $\mathrm{Mg}^{2+}$ and $\mathrm{Ca}^{2+}$ contained typographic inconsistencies, ${ }^{28}$ results from that work (thermodynamic energy, structural analysis, etc.) are obtained from parameters consistent with Table 2. Figure 4 compares CSOV polarization energy calculations with the AMOEBA polarizable force field as a function of distance between the cation and water. The difference between the two 
methods is mainly found at distances between $2-3 \AA$, where the charge transfer effect in the two-body system is strong. However, such discrepancy is expected to diminish in bulk water as the charge transfer effect is expected to be less important as explained above. Comparison between total binding energies of the AMOEBA polarizable model and ab initio calculations are shown in Figure 5. As expected, the interaction energy between 2 and $3.5 \AA$ appears to be underestimated (less negative) compared to ab initio result. The strategy here is, however, not to over-fit the AMOEBA model to the monoligated $\mathrm{Zn}^{2+}$ complex as the polarization energy and total interaction energy are already very reasonable considering the relatively simple force field functional form. The AMOEBA association energies for $\left[\mathrm{Zn}\left(\mathrm{H}_{2} \mathrm{O}\right)_{6}\right]_{2+},\left[\mathrm{Zn}\left(\mathrm{H}_{2} \mathrm{O}\right)_{5}\left(\mathrm{H}_{2} \mathrm{O}\right)\right]_{2+}$ and $\left[\mathrm{Zn}\left(\mathrm{H}_{2} \mathrm{O}\right)_{4}\left(\mathrm{H}_{2} \mathrm{O}\right)_{2}\right]_{2}$ complexes are -334.4, -333.4, and $-331.9 /-333.7 \mathrm{kcal} / \mathrm{mol}$, respectively. Given that AMOEBA is mainly targeting condensed phase, the trend observed here is in reasonable agreement with the previous $a b$ initio results $(-345.3,-341.3,-337.4 /-337.8 \mathrm{kcal} / \mathrm{mol}$ using CEP $4-31 \mathrm{G}(2 \mathrm{~d})$ basis set; $-365.9,-363.3,-360.0,-362.4 \mathrm{kcal} / \mathrm{mol}$ using $6-311 \mathrm{G}^{* *}$ basis set). ${ }^{62}$ Our approach is further validated in the condensed-phase hydration properties calculation next.

\section{Evaluation of $\mathrm{Zn}^{2+}$ Solvation in Water Using AMOEBA}

The hydration free energy is the key quantity describing the thermodynamic stability of an ion in solution. The solvation free energy of zinc in water has been computed from molecular dynamics simulations using free energy perturbation (FEP). Table 3 lists the free energy of hydration for $\mathrm{Zn}^{2+}, \mathrm{Mg}^{2+}$, and $\mathrm{Ca}^{2+}$ compared with experiment-derived values ${ }^{66}$, 67 and the results from the quasi-chemical approximation method. ${ }^{14}$ The free energy values computed from AMOEBA are closer to those from quasi-chemical approximation (QCA) than to the data interpreted from experimental measurement. In the QCA method, the region around the solute of interest is partitioned into inner and outer shell domains. The inner shell is treated quantum mechanically while the outer shell was evaluated using a dielectric continuum model. Note that to decompose the hydration free energy of a neutral ion-pair, tetraphenylarsonium tetraphenylborate (TATB) has been most widely chosen as a reference salt, based on the extra thermodynamic assumption that the large and hydrophobic ions do not produce charge-specific solvent ordering effects..$^{55,66}$ Our results show better agreement with "experimental values" for $\mathrm{Ca}^{2+}$ and $\mathrm{Mg}^{2+}$ ions by Schmid who derived the single ion hydration free energy by using the theoretically determined proton hydration free energy as a reference. ${ }^{67}$ The hydration free energy for $\mathrm{Zn}^{2+}$ ion computed using AMOEBA is in good agreement with values given by Marcus ${ }^{66}$ and Asthagiri et al., ${ }^{14}$ with deviations less than $1.9 \%$ and $0.2 \%$, respectively.

\section{Solvent Structure and Dynamics}

To characterize the structure of water molecules around the ion, the radial distribution function (RDF) between the $\mathrm{Zn}^{2+}$ and oxygen atom of water molecule has been obtained from the 2.7-ns molecular dynamics simulation (Figure 6). The running integration of $\mathrm{Zn}-\mathrm{O}$, which imparts water-ion coordination information, is also plotted. The first minimum in the ion-O RDF is at a distance of $2.85 \AA$, which can be interpreted as the effective "size" of the complex composed of the ion and first water solvent shell. The running integration indicates a water-coordination number of 6 in the first solvation shell, which is consistent with experimental observations. ${ }^{68-73}$ As expected, the zinc cation binds to the first water shell more tightly than other ions, as evident in the more pronounced and narrow first peak as well as the shortest separation as shown in the ion-O RDFs in Figure 7. Overall the zinc solvation structure show greater similarity to $\mathrm{Mg}^{2+}$ than $\mathrm{Ca}^{2+}$.

The Born theory of ion solvation ${ }^{74}$ states that there exists an effective solvation radius, $R_{\mathrm{B}}$, for each ion such that the solvation free energy of the ion in a dielectric medium is given by 


$$
\Delta A=-\frac{q^{2}}{2 R_{B}}\left(1-\frac{1}{\varepsilon_{d}}\right)
$$

where $q$ is the charge of the ion and $\varepsilon_{d}$ is the dielectric constant of the medium ( 80 for water). We have calculated the effective radius of zinc based on the Born equation from the solvation free energy obtained from our simulations. Table 4 gives a detailed comparison among $\mathrm{Zn}^{2+}, \mathrm{Mg}^{2+}$ and $\mathrm{Ca}^{2+}$. It should be noted, however, that previous studies have shown ion hydration energy is not symmetric with respect to electronegativity ${ }^{27,75,76}$ as is implied by the Born theory. The first peak of the $\mathrm{Zn}^{2+}$-O RDF is at $1.98 \AA$ and the effective Born radius of the cation is calculated to be $1.47 \AA$. A difference of $\sim 0.5 \AA$ between the two quantities is consistent with the results of other mono- and divalent metal ions. ${ }^{27,}$ 28, 77-79 The difference between the first minimum in the $\mathrm{Zn}^{2+}{ }_{-} \mathrm{O} \mathrm{RDF}$ and the Born radius is $1.38 \AA$ and is consistent with studies of other ions as well. ${ }^{27,} 28$

In addition to the RDF, the solvation structure has been analyzed from the distribution of the angles formed by $\mathrm{O}-$ ion-O in the first water shell. Figure 8 compares the distribution of angles for $\mathrm{Zn}^{2+}, \mathrm{Mg}^{2+}$, and $\mathrm{Ca}^{2+}$ cations. With sharp peaks located near $90^{\circ}$ and $180^{\circ}$, the distribution of $\mathrm{O}-\mathrm{Zn}^{2+}-\mathrm{O}$ angle suggests a rigid octahedron geometry with the $\mathrm{Zn}^{2+}$ surrounded by six water molecules. $\mathrm{Mg}^{2+}$ shares a similar but slightly more flexible geometry, while results for $\mathrm{Ca}^{2+}$ suggest a more amorphous structure. Figure 10 is a sample frame from the molecular dynamics simulation to illustrate the octahedron arrangement between the zinc and the first shell water molecules.

\section{Dipole Moment}

The average dipole moment of water as a function of distance away from the zinc cation is computed. At the closest distance of 1.9-2.5 $\AA$ water experiences dipole moment from 3.03.9D. Due to the highly organized structure of the first water shell, a "vacuum" space free of water molecules is observed between 2.6-3.2 $\AA$ away from the cation, also evident in the $\mathrm{Zn}^{2+}-\mathrm{O}$ RDF. The higher dipole moment of $\mathrm{Zn}^{2+}$ relative to bulk water $\left(2.77 \mathrm{D}^{36}\right)$ within the first water shell is consistent with previous observation of other divalent cations. ${ }^{28}$ The dipole moment of water in the first solvation shell of monovalent cations such as $\mathrm{K}^{+}$and $\mathrm{Na}^{+}$, however, is lower than that of bulk water. ${ }^{55}$

\section{Residence Time}

We have investigated the lifetime of ion-water coordination by directly examining the average amount of time that a water molecule resides within the first solvation shell. The first solvation shell is determined by position of the first minimum of the Zn-O RDF. If an oxygen atom is less than $2.85 \AA$ away from the $\mathrm{Zn}^{2+}$, the water is considered to be in the first solvation shell. Cutoff distances used for the first solvation shells of $\mathrm{Mg}^{2+}$ and $\mathrm{Ca}^{2+}$ are $2.95 \AA$ and $3.23 \AA$, respectively. In Table 5, coordination numbers and residence times from AMOEBA simulations are compared with experimental values for $\mathrm{Zn}^{2+}, \mathrm{Mg}^{2+}$ and $\mathrm{Ca}^{2+}$. 20 , ${ }^{80-86} \mathrm{The}^{\mathrm{Zn}}{ }^{2+}$ to water-proton dynamics are studied with quasi-elastic neutron scattering methods (QENS) as described by Salmon. ${ }^{80}$ The water residence times directly sampled from the MD simulations are in better agreement with experimental results than those previously inferred from the time correlation function of the instantaneous first shell coordination number. ${ }^{28}$ According to AMOEBA simulations, the residence time in the first solvation shell around $\mathrm{Zn}^{2+}$ is at least $2 \mathrm{~ns}$ and the water molecules around $\mathrm{Ca}^{2+}$ have a life time on the order of several ps, both of which are within the experimental ranges. For $\mathrm{Mg}^{2+}$, experiment suggests that water molecules could live up to a few $\mu$ s while the simulations using AMOEBA indicates a residence time similar to that of $\mathrm{Zn}^{2+}$. Classical fixed-charge 
molecular mechanic methods suggest a residence time of $146 \mathrm{ps}^{87}$ for water around $\mathrm{Zn}^{2+}$, while quantum mechanical methods have not attained simulation times long enough to observe the exchange of water molecules in the first shell. ${ }^{68,88}$ The calculated water residence times are consistent with the analyses of radial distribution function and water angle distribution. A longer residence time is accompanied by a more ordered and closely packed water structure near the cation.

\section{Conclusions}

We showed in this contribution that AMOEBA was able to provide a reasonably accurate description of $\mathrm{Zn}^{2+}$ interaction with water, especially in the bulk water environment. We explained in detail one of the reasons for such good performance - the ab initio calculations demonstrated that the relative importance of charge transfer diminishes as the number of water molecule increases, a sign of anti-cooperativity. We have established a fitting strategy for induction: charge transfer can be included into the pair-wise dispersion in the van der Waals contribution; incorporation of charge transfer into polarization would lead to an overestimation of the many-body effects. Despite the difficulty of the AMOEBA model to reproduce the binding energy of the monoligated $\mathrm{Zn}^{2+}$-water complex, which exhibits nonclassical covalent bonding as shown by ELF topological analysis, AMOEBA is able to afford robust estimation of the hydration free energy along with reasonable solvation structure and dynamics. The current and previous studies suggest that the classical polarizable multipole-based AMOEBA is an effective tool to model ion in bulk solution as good relative solvation free energies, structure and dynamic properties have been obtained for a range of mono- and divalent cations. The work clearly demonstrates the need of "interpretative" ab initio techniques (ELF, EDA methods) in order to follow a bottom-up approach going from the gas phase $a b$ initio calculations to condensed-phase MD simulations. In addition, the zinc model developed in this work opens the door for future study of zinc-containing metalloproteins. Further investigation is necessary to determine whether the presence of negatively charged species interacting with $\mathrm{Zn}^{2+}$ would require an explicit consideration of charge transfer contribution in the classical energy function.

\section{Supplementary Material}

Refer to Web version on PubMed Central for supplementary material.

\section{Acknowledgments}

This research was supported by grants from the National Institute of General Medical Sciences (R01GM079686) and Robert A. Welch Foundation (F-1691) to PR. This work was also supported by the French National Research Agency (ANR) on project LASIHMODo (ANR-08-BLAN-0158-01) (JPP). Some computations have been carried out at GENCI IDRIS (F. 91403 Orsay, France) and CRIHAN (F. 76800 Saint-Etienne-de-Rouvray, France) supercomputer centers.

\section{References}

1. Keilin D, Mann T. Carbonic anhydrase. Purification and nature of the enzyme. Biochem J 1940;34:1163-1176. [PubMed: 16747299]

2. Maynard AT, Covell DG. Reactivity of zinc finger cores: Analysis of protein packing and electrostatic screening. J Am Chem Soc 2001;123:1047-1058. [PubMed: 11456658]

3. Lipscomb WN, Strater N. Recent advances in zinc enzymology. Chem Rev (Washington, DC, U S) 1996;96:2375-2433.

4. De Courcy B, Gresh N, Piquemal JP. Importance of lone pair interactions/redistribution in hard and soft ligands within the active site of alcohol dehydrogenase $\mathrm{Zn}$-metalloenzyme: Insights from electron localization function. Interdisc Sci: Comput Life Sci 2009;1:55-60. 
5. Gresh N, Garmer DR. Comparative binding energetics of $\mathrm{Mg} 2+, \mathrm{Ca} 2+, \mathrm{Zn} 2+$, and $\mathrm{Cd} 2+$ to biologically relevant ligands: Combined ab initio SCF supermolecule and molecular mechanics investigation. J Comput Chem 1996;17:1481-1495.

6. Rayon VM, Valdes H, Diaz N, Suarez D. Monoligand Zn(II) complexes: Ab initio benchmark calculations and comparison with density functional theory methodologies. J Chem Theory Comput 2008;4:243-256.

7. Amin EA, Truhlar DG. Zn coordination chemistry: Development of benchmark suites for geometries, dipole moments, and bond dissociation energies and their use to test and validate density functionals and molecular orbital theory. J Chem Theory Comput 2008;4:75-85.

8. Warshel A, Levitt M. Theoretical studies of enzymic reactions - dielectric, electrostatic and steric stabilization of carbonium-ion in reaction of lysozyme. J Mol Biol 1976;103:227-249. [PubMed: 985660]

9. Estiu G, Suarez D, Merz KM. Quantum mechanical and molecular dynamics simulations of ureases and Zn beta-lactamases. J Comput Chem 2006;27:1240-1262. [PubMed: 16773613]

10. Friesner RA, Guallar V. Ab initio quantum chemical and mixed quantum mechanics/molecular mechanics (QM/MM) methods for studying enzymatic catalysis. Annu Rev Phys Chem 2005;56:389-427. [PubMed: 15796706]

11. Ryde U. Combined quantum and molecular mechanics calculations on metalloproteins. Curr Opin Chem Biol 2003;7:136-142. [PubMed: 12547438]

12. Tuccinardi T, Martinelli A, Nuti E, Carelli P, Balzano F, Uccello-Barretta G, Murphy G, Rossello A. Amber force field implementation, molecular modelling study, synthesis and MMP-1/MMP-2 inhibition profile of (R)and (S)-N-hydroxy-2-(N-isopropoxybiphenyl-4-ylsulfonamido)-3methylbutanamides. Bioorg Med Chem 2006;14:4260-4276. [PubMed: 16483784]

13. Yuan-Ping P. Successful molecular dynamics simulation of two zinc complexes bridged by a hydroxide in phosphotriesterase using the cationic dummy atom method. Proteins: Struct, Funct Genet 2001;45:183-189. [PubMed: 11599021]

14. Asthagiri D, Pratt LR, Paulaitis ME, Rempe SB. Hydration structure and free energy of biomolecularly specific aqueous dications, including $\mathrm{Zn} 2+$ and first transition row metals. J Am Chem Soc 2004;126:1285-1289. [PubMed: 14746502]

15. Rogers DM, Beck TL. Quasichemical and structural analysis of polarizable anion hydration. J Chem Phys 2010;132:014505. [PubMed: 20078170]

16. Gresh N, Cisneros GA, Darden TA, Piquemal JP. Anisotropic, polarizable molecular mechanics studies of inter- and intramoecular interactions and ligand-macromolecule complexes. A bottomup strategy. J Chem Theory Comput 2007;3:1960-1986. [PubMed: 18978934]

17. Cisneros, GA.; Darden, TA.; Gresh, N.; Pilmé, J.; Reinhardt, P.; Parisel, O.; Piquemal, JP. Multiscale Quantum Models for Biocatalysis. Vol. 7. Springer; Netherlands: 2009. Design Of Next Generation Force Fields From AB Initio Computations: Beyond Point Charges Electrostatics; p. 137-172.

18. Ren PY, Ponder JW. Consistent treatment of inter- and intramolecular polarization in molecular mechanics calculations. J Comput Chem 2002;23:1497-1506. [PubMed: 12395419]

19. de Courcy B, Piquemal JP, Gresh N. Energy Analysis of Zn Polycoordination in a Metalloprotein Environment and of the Role of a Neighboring Aromatic Residue. What Is the Impact of Polarization? J Chem Theory Comput 2008;4:1659-1668.

20. Roux C, Gresh N, Perera L, Piquemal J, Salmon L. Binding of 5-phospho-Darabinonohydroxamate and 5-phospho-D-arabinonate inhibitors to zinc phosphomannose isomerase from Candida albicans studied by polarizable molecular mechanics and quantum mechanics. J Comput Chem 2007;28:938-957. [PubMed: 17253648]

21. Jenkins L, Hara T, Durell S, Hayashi R, Inman J, Piquemal J, Gresh N, Appella E. Specificity of acyl transfer from 2-mercaptobenzamide thioesters to the HIV-1 nucleocapsid protein. J Am Chem Soc 2007;129:11067-11078. [PubMed: 17705474]

22. Gresh N, Piquemal J, Krauss M. Representation of Zn(II) complexes in polarizable molecular mechanics. Further refinements of the electrostatic and short-range contributions. Comparisons with parallel ab initio computations. J Comput Chem 2005;26:1113-1130. [PubMed: 15934064] 
23. Antony J, Piquemal JP, Gresh N. Complexes of thiomandelate and captopril mercaptocarboxylate inhibitors to metallo-beta-lactamase by polarizable molecular mechanics. Validation on model binding sites by quantum chemistry. J Comput Chem 2005;26:1131-1147. [PubMed: 15937993]

24. Jiao D, Golubkov PA, Darden TA, Ren P. Calculation of protein-ligand binding free energy by using a polarizable potential. Proc Natl Acad Sci U S A 2008;105:6290-6295. [PubMed: 18427113]

25. Jiao D, Zhang JJ, Duke RE, Li GH, Schnieders MJ, Ren PY. Trypsin-Ligand Binding Free Energies from Explicit and Implicit Solvent Simulations with Polarizable Potential. J Comput Chem 2009;30:1701-1711. [PubMed: 19399779]

26. Ponder JW, Wu CJ, Ren PY, Pande VS, Chodera JD, Schnieders MJ, Haque I, Mobley DL, Lambrecht DS, DiStasio RA, Head-Gordon M, Clark GNI, Johnson ME, Head-Gordon T. Current Status of the AMOEBA Polarizable Force Field. J Phys Chem B 2010;114:2549-2564. [PubMed: 20136072]

27. Grossfield A. Dependence of ion hydration on the sign of the ion's charge. J Chem Phys 2005;122:024506. [PubMed: 15638597]

28. Jiao D, King C, Grossfield A, Darden TA, Ren PY. Simulation of $\mathrm{Ca} 2+$ and $\mathrm{Mg} 2+$ solvation using polarizable atomic multipole potential. J Phys Chem B 2006;110:18553-18559. [PubMed: 16970483]

29. Piquemal JP, Perera L, Cisneros GA, Ren PY, Pedersen LG, Darden TA. Towards accurate solvation dynamics of divalent cations in water using the polarizable amoeba force field: From energetics to structure. J Chem Phys 2006;125:054511. [PubMed: 16942230]

30. Bagus PS, Illas F. Decomposition of the chemisorption bond by constrained variations - Order of the variations and construction of the variational spaces. J Chem Phys 1992;96:8962-8970.

31. Stevens WJ, Fink WH. Frozen fragment reduced variational space analysis of hydrogen-bonding interactions - Application to the water dimer. Chem Phys Lett 1987;139:15-22.

32. Jeziorski B, Moszynski R, Szalewicz K. Perturbation-theory approach to intermolecular potentialenergy surfaces of van-der-Waals complexes. Chem Rev (Washington, DC, U S) 1994;94:1887_ 1930.

33. Becke AD, Edgecombe KE. A simple measure of electron localization in atomic and molecularsystems. J Chem Phys 1990;92:5397-5403.

34. Silvi B, Savin A. Classification of chemical-bonds based on topological analysis of electron localization functions. Nature 1994;371:683-686.

35. Frisch, MJ.; Trucks, GW.; Schlegel, HB.; Scuseria, GE.; Robb, MA.; Cheeseman, JR.; Montgomery, JAJ.; Vreven, T.; Kudin, KN.; Burant, JC.; Millam, JM.; Iyengar, SS.; Tomasi, J.; Barone, V.; Mennucci, B.; Cossi, M.; Scalmani, G.; Rega, N.; Petersson, GA.; Nakatsuji, H.; Hada, M.; Ehara, M.; Toyota, K.; Fukuda, R.; Hasegawa, J.; Ishida, M.; Nakajima, T.; Honda, Y.; Kitao, O.; Nakai, H.; Klene, M.; Li, X.; Knox, JE.; Hratchian, HP.; Cross, JB.; Bakken, V.; Adamo, C.; Jaramillo, J.; Gomperts, R.; Stratmann, RE.; Yazyev, O.; Austin, AJ.; Cammi, R.; Pomelli, C.; Ochterski, JW.; Ayala, PY.; Morokuma, K.; Voth, GA.; Salvador, P.; Dannenberg, JJ.; Zakrzewski, VG.; Dapprich, S.; Daniels, AD.; Strain, MC.; Farkas, O.; Malick, DK.; Rabuck, AD.; Raghavachari, K.; Foresman, JB.; Ortiz, JV.; Cui, Q.; Baboul, AG.; Clifford, S.; Cioslowski, J.; Stefanov, BB.; Liu, G.; Liashenko, A.; Piskorz, P.; Komaromi, I.; Martin, RL.; Fox, DJ.; Keith, T.; Al-Laham, MA.; Peng, CY.; Nanayakkara, A.; Challacombe, M.; Gill, PMW.; Johnson, B.; Chen, W.; Wong, MW.; Gonzalez, C.; Pople, JA. Gaussian 03, Revision D01. Gaussian, Inc; Wallingford, CT: 2004.

36. Ren PY, Ponder JW. Polarizable atomic multipole water model for molecular mechanics simulation. J Phys Chem B 2003;107:5933-5947.

37. Ren PY, Ponder JW. Temperature and pressure dependence of the AMOEBA water model. J Phys Chem B 2004;108:13427-13437.

38. Dunning TH. Gaussian-Basis Sets for Use in Correlated Molecular Calculations.1. The Atoms Boron through Neon and Hydrogen. J Chem Phys 1989;90:1007-1023.

39. Helgaker, T.; Jørgensen, P.; Olsen, J.; Ruud, K.; Andersen, T.; Bak, KL.; Bakken, V.; Christiansen, O.; Dahle, P.; Dalskov, EK.; Enevoldsen, T.; Heiberg, H.; Hettema, H.; Jonsson, D.; Kirpekar, S.; 
Kobayashi, R.; Koch, H.; Mikkelsen, KV.; Norman, P.; Packer, MJ.; Saue, T.; Taylor, PR.; Vahtras, O.; Jensen, HJA.; Ågren, H. Dalton, an Ab Initio Electronic Structure Program, 1.0. 1997.

40. Piquemal J, Marquez A, Parisel O, Giessner-Prettre C. A CSOV study of the difference between HF and DFT intermolecular interaction energy values: The importance of the charge transfer contribution. J Comput Chem 2005;26:1052-1062. [PubMed: 15898112]

41. Becke AD. Density-Functional Exchange-Energy Approximation with Correct AsymptoticBehavior. Phys Rev A 1988;38:3098-3100. [PubMed: 9900728]

42. Lee CT, Yang WT, Parr RG. Development of the Colle-Salvetti Correlation-Energy Formula into a Functional of the Electron-Density. Physical Review B 1988;37:785-789.

43. Gordon, MS.; Schmidt, MW. Advances in electronic structure theory: GAMESS a decade later. In: Dykstra, CE.; Frenking, G.; Kim, KS.; Scuseria, GE., editors. Theory and Applications of Computational Chemistry, the first forty years. Elsevier; Amsterdam: 2005.

44. Stevens WJ, Basch H, Krauss M. Compact Effective Potentials and Efficient Shared-Exponent Basis-Sets for the 1st-Row and 2nd-Row Atoms. J Chem Phys 1984;81:6026-6033.

45. Savin A, Nesper R, Wengert S, Fassler TF. ELF: The electron localization function. Angewandte Chemie-International Edition in English 1997;36:1809-1832.

46. de Courcy B, Pedersen LG, Parisel O, Gresh N, Silvi B, Pilme J, Piquemal JP. Understanding Selectivity of Hard and Soft Metal Cations within Biological Systems Using the Subvalence Concept. 1. Application to Blood Coagulation: Direct Cation-Protein Electronic Effects versus Indirect Interactions through Water Networks. J Chem Theory Comput 2010;6:1048-1063. [PubMed: 20419068]

47. Piquemal JP, Pilme J, Parisel O, Gerard H, Fourre I, Berges J, Gourlaouen C, De La Lande A, Van Severen MC, Silvi B. What can be learnt on biologically relevant systems from the topological analysis of the electron localization function? Int J Quantum Chem 2008;108:1951-1969.

48. Pilme J, Piquemal JP. Advancing beyond charge analysis using the electronic localization function: Chemically intuitive distribution of electrostatic moments. J Comput Chem 2008;29:1440-1449. [PubMed: 18293309]

49. Noury S, Krokidis X, Fuster F, Silvi B. Computational tools for the electron localization function topological analysis. Comput Chem 1999;23:597-604.

50. Claverie, P. Intermolecular Interactions: From Diatomics to Biopolymers. Vol. 1. Wiley; New York, USA: 1978.

51. Kutzelnigg W. The primitive wavefunction in the theory of intermolecular interactions. J Chem Phys 1980;73:343-359.

52. Reinhardt, P.; Piquemal, J. New Intermolecular Benchmark Calculations on the Water Dimer: SAPT and Supermolecular Post-Hartree-Fock Approaches. 6th Congress of the InternationalSociety-for-Theoretical-Chemical-Physics; NOV 15 2009; 2009. p. 3259-3267.

53. Halgren TA. Representation of van der Waals ( $\mathrm{vdW}$ ) interactions in molecular mechanics forcefields - potential form, combination rules, and vdW parameters. J Am Chem Soc 1992;114:78277843.

54. Masia M, Probst M, Rey R. On the performance of molecular polarization methods. II. Water and carbon tetrachloride close to a cation. J Chem Phys 2005;123:164505. [PubMed: 16268710]

55. Grossfield A, Ren PY, Ponder JW. Ion solvation thermodynamics from simulation with a polarizable force field. J Am Chem Soc 2003;125:15671-15682. [PubMed: 14664617]

56. Ponder, J. TINKER: Software Tools for Molecular Design, Version 5.0. Saint Louis, MO: 2009.

57. Sagui C, Pedersen LG, Darden TA. Towards an accurate representation of electrostatics in classical force fields: Efficient implementation of multipolar interactions in biomolecular simulations. J Chem Phys 2004;120:73-87. [PubMed: 15267263]

58. Berendsen HJC, Postma JPM, van Gunsteren WF, DiNola A, Haak JR. Molecular Dynamics with Coupling to an External Bath. J Chem Phys 1984;81:3684-3690.

59. Bennett CH. Efficient Estimation of Free-Energy Differences from Monte-Carlo Data. J Comput Phys 1976;22:245-268.

60. Shirts MR, Bair E, Hooker G, Pande VS. Equilibrium free energies from nonequilibrium measurements using maximum-likelihood methods. Phys Rev Lett 2003;91:140601, 1-4. [PubMed: 14611511] 
61. Gresh N. Energetics of Zn2+ Binding to a Series of Biologically Relevant Ligands - a Molecular Mechanics Investigation Grounded on Ab-Initio Self-Consistent-Field Supermolecular Computations. J Comput Chem 1995;16:856-882.

62. Tiraboschi G, Gresh N, Giessner-Prettre C, Pedersen LG, Deerfield DW. Parallel ab initio and molecular mechanics investigation of polycoordinated $\mathrm{Zn}$ (II) complexes with model hard and soft ligands: Variations of binding energy and of its components with number and charges of ligands. J Comput Chem 2000;21:1011-1039.

63. Stone, AJ. The Theory of Intermolecular Forces. Oxford University Press; USA: 1997.

64. Zhao Z, Rogers DM, Beck TL. Polarization and charge transfer in the hydration of chloride ions. J Chem Phys 2010;132:014502. [PubMed: 20078167]

65. Reinhardt P, Piquemal J, Savin A. Fragment-Localized Kohn-Sham Orbitals via a Singles Configuration-interaction Procedure and Application to Local Properties and Intermolecular Energy Decomposition Analysis. J Chem Theory Comput 2008;4:2020-2029.

66. Marcus Y. A Simple Empirical-Model Describing the Thermodynamics of Hydration of Ions of Widely Varying Charges, Sizes, and Shapes. Biophys Chem 1994;51:111-127.

67. Schmid R, Miah AM, Sapunov VN. A new table of the thermodynamic quantities of ionic hydration: values and some applications (enthalpy-entropy compensation and Born radii). Phys Chem Chem Phys 2000;2:97-102.

68. Mohammed AM, Loeffler HH, Inada Y, Tanada K-i, Funahashi S. Quantum mechanical/molecular mechanical molecular dynamic simulation of zinc(II) ion in water. J Mol Liq 2005;119:55-62.

69. D'Angelo P, Barone V, Chillemi G, Sanna N, Meyer-Klaucke W, Pavel NV. Hydrogen and Higher Shell Contributions in Zn2+, Ni2+, and Co2+ Aqueous Solutions: An X-ray Absorption Fine Structure and Molecular Dynamics Study. J Am Chem Soc 2002;124:1958-1967. [PubMed: 11866609]

70. Obst S, Bradaczek H. Molecular dynamics simulations of zinc ions in water using CHARMM. J Mol Model 1997;3:224-232.

71. Kuzmin A, Obst S, Purans J. X-ray absorption spectroscopy and molecular dynamics studies of Zn2+ hydration in aqueous solutions. J Phys : Condens Matter 1997;9:10065-10078.

72. Marini GW, Texler NR, Rode BM. Monte Carlo simulations of Zn(II) in water including threebody effects. J Phys Chem 1996;100:6808-6813.

73. Yongyai YP, Kokpol S, Rode BM. Zinc Ion in Water - Intermolecular Potential with Approximate 3-Body Correction and Monte-Carlo Simulation. Chem Phys 1991;156:403-412.

74. Born M. Volumen und Hydratationswärme der Ionen. Zeitschrift für Physik A Hadrons and Nuclei 1920;1:45-48.

75. Garde S, Hummer G, Paulaitis ME. Free energy of hydration of a molecular ionic solute: Tetramethylammonium ion. J Chem Phys 1998;108:1552-1561.

76. Rajamani S, Ghosh T, Garde S. Size dependent ion hydration, its asymmetry, and convergence to macroscopic behavior. J Chem Phys 2004;120:4457-4466. [PubMed: 15268613]

77. Naor MM, Van Nostrand K, Dellago C. Car-Parrinello molecular dynamics simulation of the calcium ion in liquid water. Chem Phys Lett 2003;369:159-164.

78. Badyal YS, Barnes AC, Cuello GJ, Simonson JM. Understanding the effects of concentration on the solvation structure of $\mathrm{Ca} 2+$ in aqueous solutions. II: Insights into longer range order from neutron diffraction isotope substitution. J Phys Chem A 2004;108:11819-11827.

79. Jalilehvand F, Spangberg D, Lindqvist-Reis P, Hermansson K, Persson I, Sandstrom M. Hydration of the calcium ion. An EXAFS, large-angle X-ray scattering, and molecular dynamics simulation study. J Am Chem Soc 2001;123:431-441. [PubMed: 11456545]

80. Salmon PS, Bellissentfunel MC, Herdman GJ. The Dynamics of Aqueous Zn-2+ Solutions - a Study Using Incoherent Quasi-Elastic Neutron-Scattering. J Phys: Condens Matt 1990;2:42974309.

81. Neely J, Connick R. Rate of water exchange from hydrated magnesium ion. J Am Chem Soc 1970;92:3476-3478.

82. Friedman H. Hydration complexes - some firm results and some pressing questions. Chemica Scripta 1985;25:42-48. 
83. Ohtaki H, Radnai T. Structure and dynamics of hydrated ions. Chem Rev (Washington, DC, U S) 1993;93:1157-1204.

84. Helm L, Merbach AE. Water exchange on metal ions: experiments and simulations. Coord Chem Rev 1999;187:151-181.

85. Caminiti R, Licheri G, Piccaluga G, Pinna G. X-ray-diffraction study of a 3-ion aqueous-solution. Chem Phys Lett 1977;47:275-278.

86. Lightstone FC, Schwegler E, Allesch M, Gygi F, Galli G. A first-principles molecular dynamics study of calcium in water. ChemPhysChem 2005;6:1745-1749. [PubMed: 16013079]

87. Fatmi MQ, Hofer TS, Randolf BR, Rode BM. An extended ab initio QM/MM MD approach to structure and dynamics of $\mathrm{Zn}(\mathrm{II})$ in aqueous solution. J Chem Phys 2005;123:054514-8. [PubMed: 16108676]

88. Fatmi MQ, Hofer TS, Randolf BR, Rode BM. Temperature Effects on the Structural and Dynamical Properties of the Zn(II)-Water Complex in Aqueous Solution: A QM/MM Molecular Dynamics Study. J Phys Chem B 2006;110:616-621. [PubMed: 16471574] 


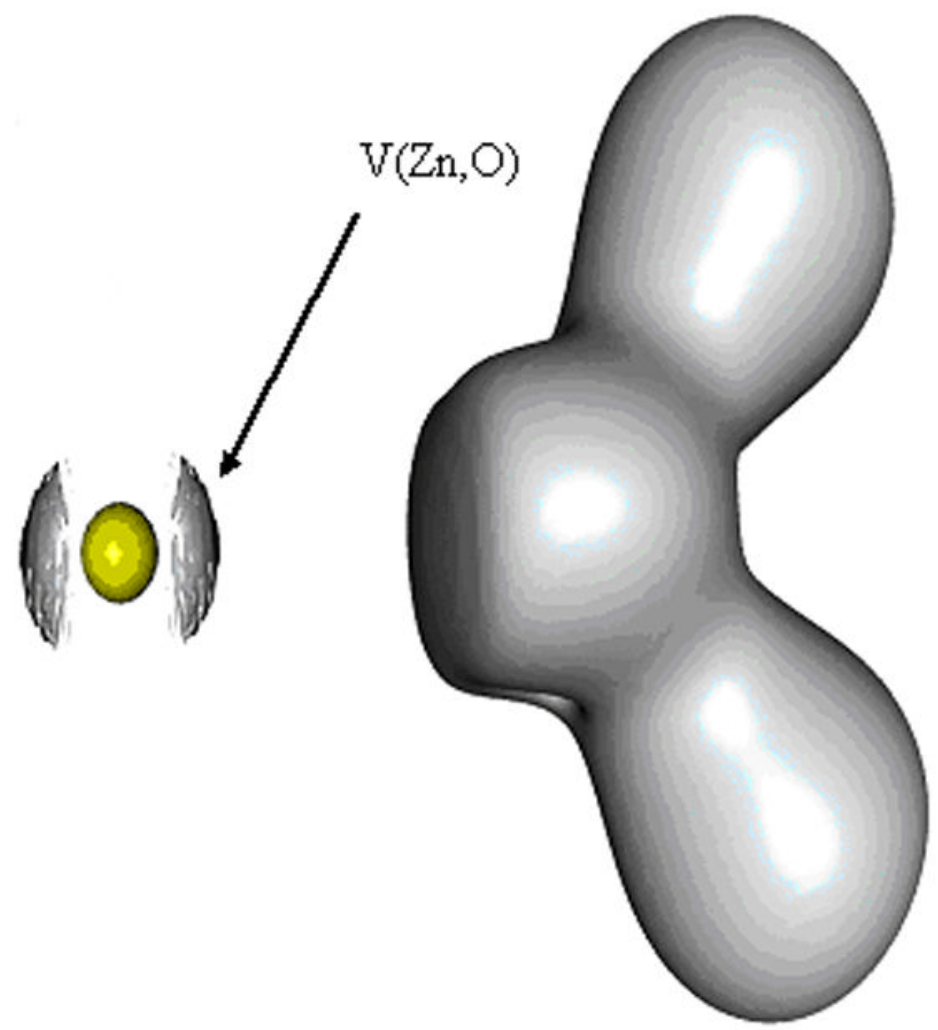

Figure 1.

ELF localization domains (basins) for the $\mathrm{Zn}^{2+}-\mathrm{H}_{2} 0$ complex. A covalent $\mathrm{V}(\mathrm{Zn}, \mathrm{O})$ basin reflecting electron sharing is observed and reveals the covalent nature of the $\mathrm{Zn}-\mathrm{O}$ interaction. 

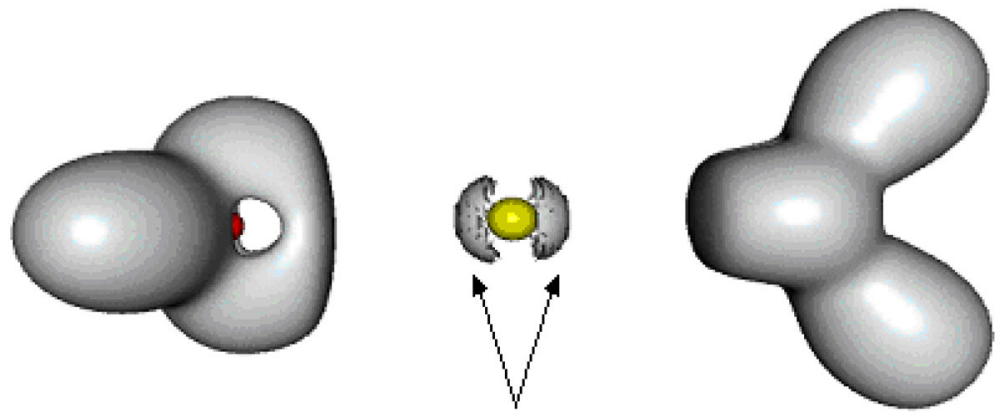

$\mathrm{V}(\mathrm{Zn})$

Figure 2.

ELF localization domains (basins) for the $\mathrm{Zn}^{2+}-\left(\mathrm{H}_{2} \mathrm{O}\right)_{2}$ complex. Non-covalent $\mathrm{V}(\mathrm{Zn})$ basin are observed describing the deformation of $\mathrm{Zn}^{2+}$ outer-shells density within the fields of the water molecules. 

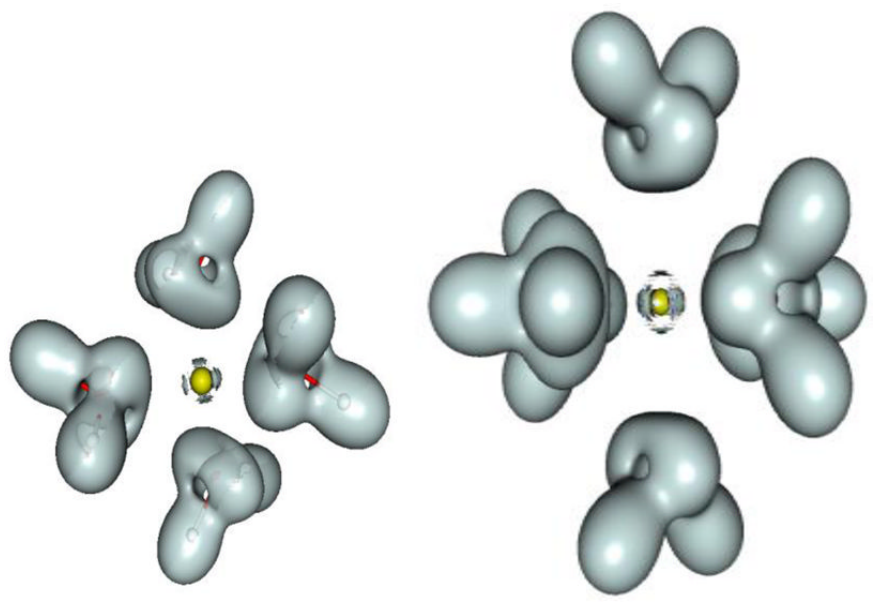

Figure 3.

ELF localization domains (basins) for the $\mathrm{Zn}^{2+}-\left(\mathrm{H}_{2} \mathrm{O}\right)_{4}$ and $\mathrm{Zn}^{2+}-\left(\mathrm{H}_{2} \mathrm{O}\right)_{6}$ complexes. Again, non covalent $\mathrm{V}(\mathrm{Zn})$ basin are observed. 


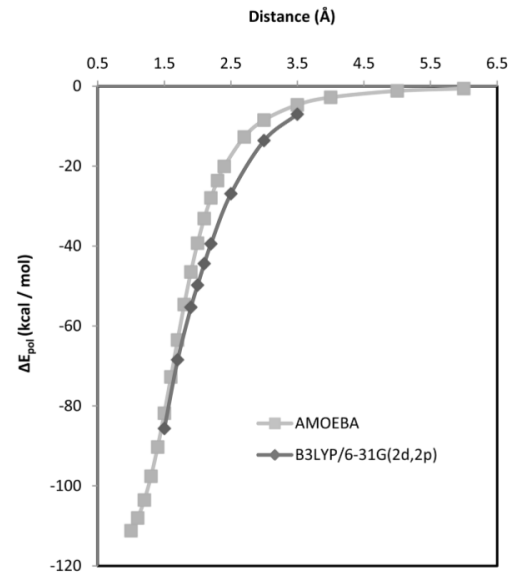

Figure 4.

Polarization energy of zinc and water dimer in gas phase as a function of separation distance. 


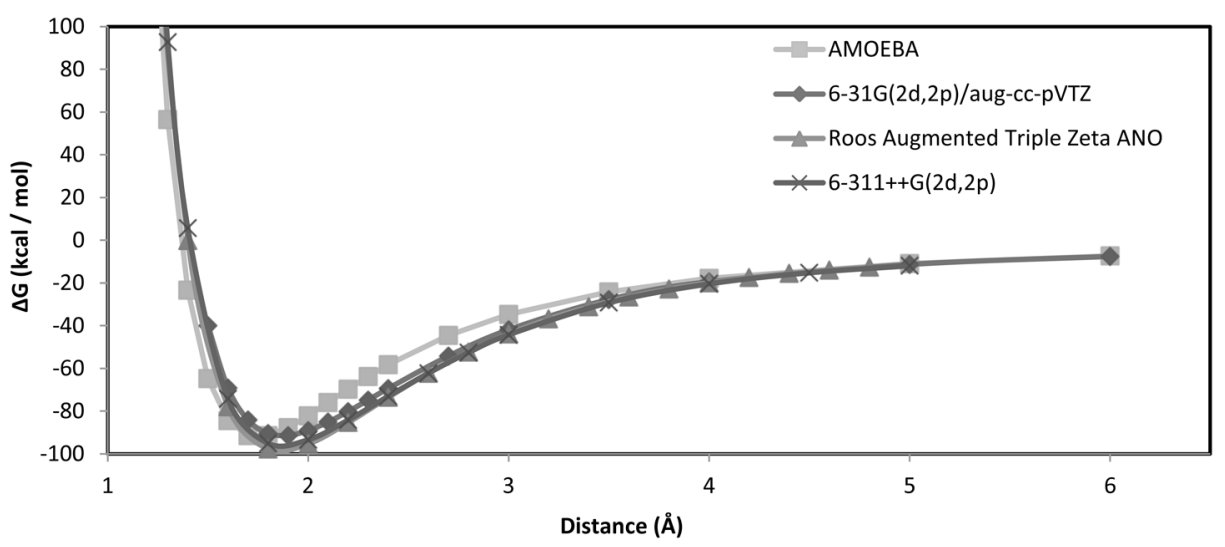

Figure 5.

Binding energy of zinc and water dimer in gas phase as a function of separation distance. The 6-31G(2d,2p)/aug-cc-pVTZ indicates that 6-31G(2d,2p) was used to represent the $\mathrm{Zn}^{2+}$ cation and aug-cc-pVTZ was used to represent the water molecule. Binding energy obtained from the last two basis sets used the same basis sets for both ion and water. 


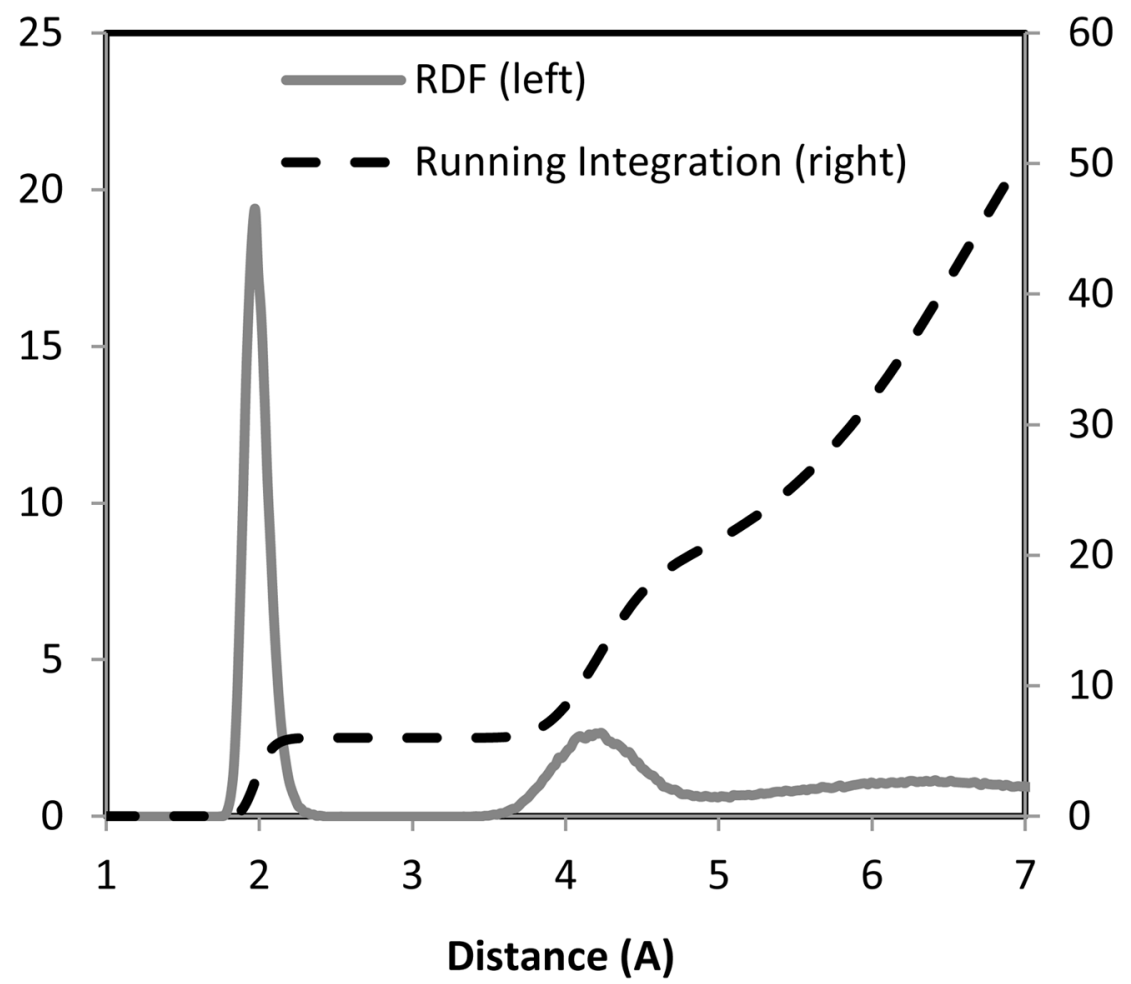

Figure 6.

Radial distribution function of $\mathrm{Zn}^{2+}-\mathrm{O}$ (left axis) and water coordination number (right axis). 


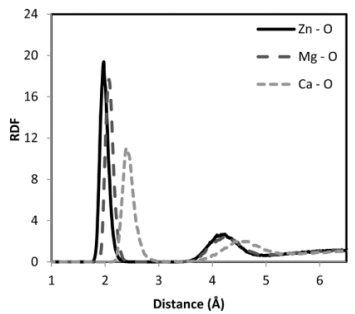

Figure 7.

Radial distribution function of divalent cations $\left(\mathrm{Zn}^{2+}, \mathrm{Mg}^{2+}\right.$, and $\left.\mathrm{Ca}^{2+}\right)$ and oxygen atom in water. 


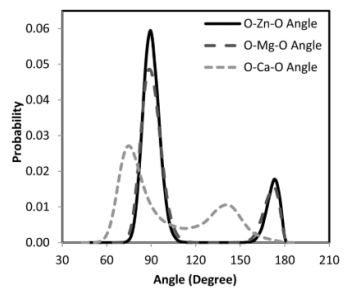

Figure 8.

Water-Ion-Water Angle distribution of divalent cations $\left(\mathrm{Zn}^{2+}, \mathrm{Mg}^{2+}\right.$, and $\left.\mathrm{Ca}^{2+}\right)$ and oxygen atom in water. 


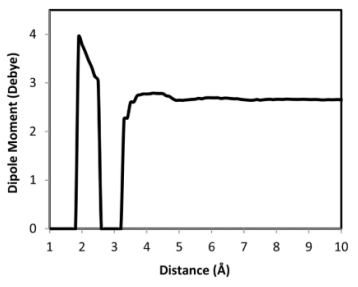

Figure 9.

Dipole moment at each distance $(\AA)$ around ion. 


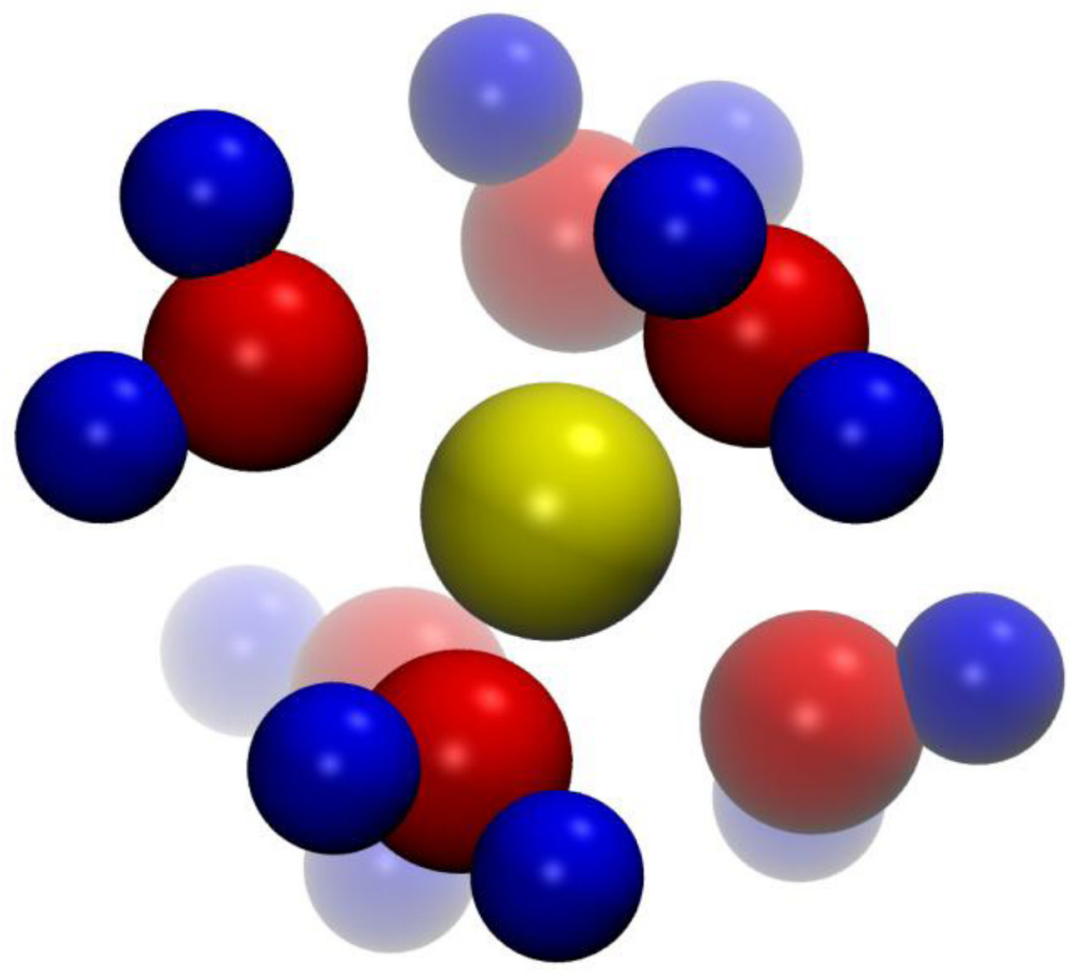

Figure 10.

First solvation shell around $\mathrm{Zn}^{2+}$ ion. 


\section{Table 1}

Polarization energy and charge transfer energy from restricted variational space (RVS) energy decomposition of $\mathrm{Zn}^{2+}$ in the presence of water clusters of sizes 1, 4, 5, and 6 at the HF/CEP-41G(2d) level (or HF/aug-ccPVTZ/6-31G**, results in parentheses). Percentage of induction energy due to charge transfer is presented in the last row. All are in units of $\mathrm{kcal} / \mathrm{mol}$.

\begin{tabular}{ccccc}
\hline Complex & $\mathbf{Z n}\left(\mathbf{H}_{\mathbf{2}} \mathbf{O}\right)$ & {$\left[\mathbf{Z n}\left(\mathbf{H}_{\mathbf{2}} \mathbf{O}\right)_{4}\right]^{2+}$} & {$\left[\mathbf{Z n}\left(\mathbf{H}_{\mathbf{2}} \mathbf{O}\right)_{5}\right]^{2+}$} & {$\left[\mathbf{Z n}\left(\mathbf{H}_{\mathbf{2}} \mathbf{O}\right)_{\mathbf{6}}\right]^{2+}$} \\
\hline $\mathrm{E}_{\mathrm{pol}}(\mathrm{RVS})$ & -37.6 & $-118.7(-135.3)$ & $-110.8(-127.5)$ & $-104.3(-117.5)$ \\
$\mathrm{E}_{\mathrm{CT}}(\mathrm{RVS})$ & -10.9 & $-28.7(-9.3)$ & $-24.5(-6.7)$ & $-21.8(-4.51)$ \\
$\left(\mathrm{E}_{\mathrm{CT}} /\left(\mathrm{E}_{\mathrm{pol}}{ }^{+} \mathrm{E}_{\mathrm{CT})}\right) * 100\right.$ & 22.5 & $19.4(6.4)$ & $18.1(5.0)$ & $16.6(3.7)$ \\
\hline
\end{tabular}




\section{Table 2}

Ion parameters are shown: diameter, well depth, polarizability and dimensionless damping coefficient.

\begin{tabular}{ccccc}
\hline Ion & $\mathbf{R}(\mathbf{\AA})$ & $\boldsymbol{\epsilon}(\mathbf{k c a l} / \mathbf{m o l})$ & $\boldsymbol{\alpha}\left(\mathbf{A}^{\mathbf{3}}\right)$ & $\boldsymbol{a}^{\boldsymbol{a}}$ \\
\hline $\mathrm{Zn}^{2+}$ & 2.68 & 0.222 & 0.260 & 0.2096 \\
$\mathrm{Mg}^{2+}$ & 2.94 & 0.300 & 0.080 & 0.0952 \\
$\mathrm{Ca}^{2+}$ & 3.63 & 0.350 & 0.550 & 0.1585 \\
\hline
\end{tabular}

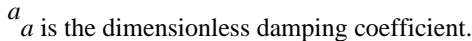


Table 3

Solvation Free Energy of Zinc in Water ${ }^{a}$

\begin{tabular}{cccc}
\hline Ion & $\Delta \mathbf{G}(\mathbf{k c a l} / \mathbf{m o l})$ & Experimental & Quasi-chemical $^{d}$ \\
\hline $\mathrm{Zn}^{2+}$ & $-458.9(4.4)$ & $-467.7^{b}$ & -460.0 \\
$\mathrm{Mg}^{2+}$ & $-431.1(2.9)$ & $-435.4^{c}$ & -435.2 \\
$\mathrm{Ca}^{2+}$ & $-354.9(1.7)$ & $-357.2^{c}$ & -356.6 \\
\hline
\end{tabular}

$a_{1 \mathrm{~mol} \mathrm{~L}}{ }^{-1}$ solution is chosen as the standard state.

${ }^{b}$ Reference 66

$c_{\text {Reference }} 67$

$d_{\text {Reference }} 14$ 


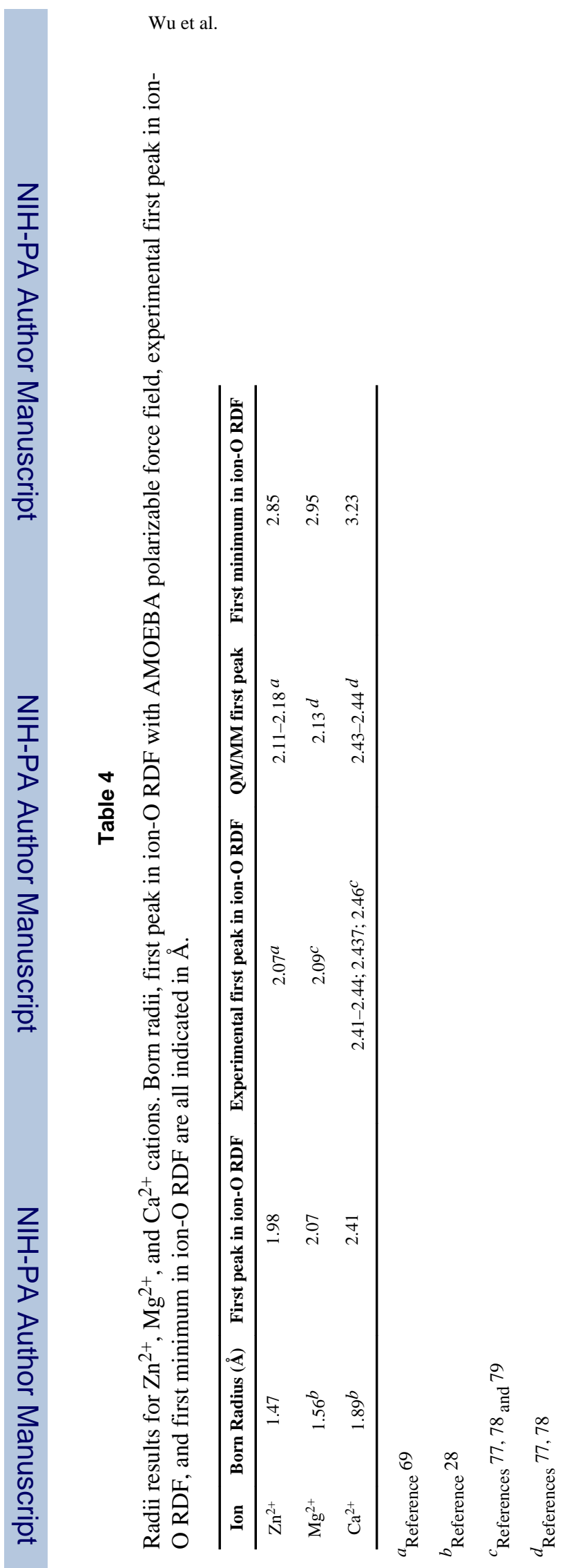

J Chem Theory Comput. Author manuscript; available in PMC 2011 July 13. 
Table 5

The coordination number, experimental coordination number, residence time, experimental residence time, and QM/MM residence times for each type of divalent cations.

\begin{tabular}{ccccc}
\hline Ion & Coordination Number & Exp. Coordination Number & Residence Time (s) & Exp Residence Time (s) \\
\hline $\mathrm{Zn}^{2+}$ & 6 & $6^{a}$ & $2.2 \times 10^{-9}$ & $10^{-10}-10^{-9 d}$ \\
$\mathrm{Mg}^{2+}$ & 6 & $6^{b}$ & $1.9 \times 10^{-9}$ & $2 \times 10^{-6}-10^{-5}$ e,f \\
$\mathrm{Ca}^{2+}$ & 7.3 & $7.2+-1.2^{c}$ & $1.33 \times 10^{-10}$ & $<10^{-10}-10^{-7 f}$ \\
\hline
\end{tabular}

$a_{\text {Reference }} 68-73$

$b_{\text {Reference }} 85$

$c_{\text {Reference }} 86$

$d_{\text {Reference }} 80$ and 20

$e_{\text {References (Neely, 1970) }}^{81}$

$f_{\text {Reference }(\text { Helm, 1999) }}{ }^{84}$, (Friedman, 1985) ${ }^{82}$ and references within (Ohtaki, 1993) 83 